\title{
Assessing the Relationship between the Perceived Business Environment and Firm's Entrepreneurial Orientation
}

\begin{abstract}
Drawing from the three dimensions of entrepreneurial orientation (3D of EO) perspectives, the paper examined the entrepreneurial orientation and performance of small and medium enterprises (SMEs) vis-à-vis the environmental embeddedness. Using multi-stage sampling technique, a total 279 firms were selected for the study at two strategic areas, Lagos and Ibadan being the hub of industrial activities in Southwestern Nigeria. The data generated was analyzed using descriptive and inferential statistics. The entrepreneurial orientation of the firms is significantly related with two environmental variables of dynamism and hostility, while the four environmental variables of dynamism, hostility, heterogeneity and munificence significantly related to the dimensional variables of entrepreneurial orientation.
\end{abstract}

*Alarape, Aderemi Ayinla.

Keywords: Entrepreneurship, Orientations, Environment, SMEs, Nigeria

\section{Introduction}

$\square_{\text {consistent set of related activities or }}^{\text {ntrepreneurial orientation describes a }}$ processes and provides a useful framework for researching entrepreneurial activity. EO is conceptualize as a firm-level strategy-making process that firms use to enact their organizational purpose, sustain their vision, and creates competitive advantages (e.g., Wiklund and Shepherd, 2003). Whereas, performance is a yardstick by which founders (i.e. entrepreneurs) measure success (Chandler and Hanks, 1994).

The performance of the firm is affected by the firm entrepreneurial orientation (Covin and Slevin, 1991; Dess, Lumpkin and Covin 1997; Rauch, Wiklund, Frese, and Lumpkin, 2004). However, the relationship between EO and performance is contingent upon the environmental variables of dynamism, hostility, heterogeneity and munificence (Lumpkin and Dess, 1996; Dess, Lumpkin and Covin, 1997; and Wiklund, 1998). However, Brown and Kirchhoff (1997) failed to identify any direct impact of the environmental variables upon the relationship between EO and performance.

The thrust of this paper is not to engage in the debate whether there is relationship between EO and performance but to shed light on the relationship between the variables (dynamism, hostility, heterogeneity and munificence) on entrepreneurial orientation and suggest ways of improving the EO by creating conducive environment, thereby, enjoy the benefits (improved performance inclusive) associated with high entrepreneurial orientation.

Literature Review
Entrepreneurial Orientation (EO) has been described as a firm-level construct (Covin and Slevin, 1991) that is closely linked to strategic management and the strategic decision making process (Burgelman, 1983; Kanter, 1982; Lumpkin and Dess, 1996; Naman and Slevin, 1993). There are two popular models of Entrepreneurial Orientation (EO). They are the three-dimension model by Covin and Slevin (1989) and the Five- dimension model by Lumpkin and Dess (1996). Each model offers a different perspective on both the concept of entrepreneurial orientation and the relationships between $\mathrm{EO}$ and other firm level characteristics. Each of the models takes into consideration the internal structure of the firm and the external environment within which the firm operates however, the representations of these factors and relationships are all different.

In developing this measure, Covin and Slevin theorized that the three dimensions (3D) of entrepreneurship orientation (EO) innovation, pro-activeness, and risk-taking acts together ase a basic uni-dimensional strategic orientation. While, Lumpkin and Dess (1996) developed the EO construct into five dimensions: autonomy, innovativeness, risk-taking, pro-activeness, and competitive aggressiveness. However, this study, while adopting the Covin and Slevin's threedimensional variables described environmental embeddedness in terms of dynamism, hostility, munificence and heterogeneity. The theoretical framework comprises of three primary components. These are: the orientation entrepreneurial units, an

${ }^{*}$ Centre for Industrial Research and Development Obafemi Awolowo University, Ile-Ife, Nigeria remialarape@yahoo.com 
independent variable that serves as the "heart" of the interactions in the models; the performance unit, a dependent variable that signifies the output of the firm;

the perceived business environment another independent variable

The entrepreneurial orientation (EO) is a behavioural construct at firm-level that is closely linked to strategic management and explains the processes, practices, and decision activities that lead to new entry in the quest of exploiting opportunities in the marketplace or shape its environment is a three dimensional construct of (i) Innovativeness, (ii) Risk-taking and (iii) Proactiveness. This is in line with other studies (Covin and Slevin, 1991; Lumpkin and Dess, 1996; Miller, 1983; Miller and Friesen, 1978; Venkatraman, 1989) on Entrepreneurial orientation and performance relationship in small and medium enterprises

Therefore, the entrepreneurial orientation of a firm reveals itself by the evidences of how innovative is the firm, the firm attitude to risk, how proactive (i.e. alert) to business opportunity and responsive to trend and development already existing in the marketplace. Consequently, the measurement of the entrepreneurial orientation is usually from three aspects:

(i) the firm manner and action towards innovation (innovativeness),

(ii) the firm risk-taking, and

(iii) the firm alertness to grasping of opportunities and responsiveness to trend and demand that already exist in market.

Aldrich et al (1999) described the environment as the initial conditions facing the entrepreneur in an economy. This perception of environment is too broad for this line of enquiry, since it would cover all the conditions facing the entrepreneur at the overall industry level, national and global levels. Therefore, in accordance with the submission of Dess and Bread (1984) that in order to concentrate on narrowly defined parts of the environment, rather than on overall industry, the perceived environment should be chosen. The Business founders (i.e. owners) and managers are the experts, whose perception has usually been used as indicators of the characteristics of the environment (Chandler and Hanks, 1998). Therefore in the present study, the perceived environment will be examined using the four concepts of "Munificence", "Dynamism", "Hostility" and "Heterogeneity". Aloulou W., Fayolle A., Lyon B.M., and France C (2005) support this approach.

A "Dynamic environment" is characterised by instability and continuous change and may be source of abundant opportunities. In such areas, there are industry growth, technology, customer preferences, and demand for new products. Of course, these are available as opportunities for small businesses. Thus, in his effort at utilising these advantages, the firm may develop innovative strategies, be more proactive and risk taking and unconsciously develop its entrepreneurial orientation, thereby positively affecting the firm performance.

Hypothesis 1: The more dynamic the perceived business environment the higher the firm's entrepreneurial orientation and performance.

A "Hostile environment" creates threats to the firm, either through increase rivalry or decrease demand for the products. The firm therefore become more proactive to beat its competitors: risk-taking and innovative in revitalising the demand of its products. Hence:

Hypothesis 2: environmental hostility is positively related entrepreneurial orientation

\section{"Environmental heterogeneity"}

indicates that there are several different segments of the market with varied characteristics and needs that is served by the firm. In order to take advantage of the heterogeneity of the business environment, the firm needs to be proactive and risk-taking and innovative in order to take advantage of potential arbitrage and connect different markets.

Hypothesis 3 environmental heterogeneity is positively related to entrepreneurial orientation

\section{"Environmental munificence"} (abundance) means a great availability of resources in the environment and great opportunity in access and acquirement of 
resources needed. This is in line with the position of Covin and Slevin (1991); and Brown and Kirchhoff, (1997). Munificence will significantly encourage innovativeness. Pro-activeness will become unimportance as the risk of failure is reduced.

Hypothesis 4: environmental munificence is positively related to entrepreneurial Orientation.

\section{Research Methods Data Collection}

The study was cross-sectional and data were collected under a non-contrived environment to analyse the relationship between the entrepreneurial orientation ( EO) and performance and the effect of the perceived business environment (PBE), on the EO. Data for the study were collected from primary and secondary sources. Primary data were collected through questionnaire administered on owners/managers of small and medium enterprises (SMEs). The questions measuring the entrepreneurial orientation construct are from Covin and Slevin (1989), Wiklund J. (1998) and Dess and Lumpkin (2005). Those assessing the environmental variable are from Miller and Friesen (1982), Zahra (1993), Chandler and Hanks (1994), Shane and Kolvereid (1995), Brown and Kirchhoff (1997) and Iakovleva (2005). The set of questions assessing the firm's resource and capabilities are from Shane and kolvereid (1995), Boch et al (1999), Spanos and Lioukas (2001).

Multi-stage sampling technique was adopted in selecting the sample size. The first-stage involved the application of cluster sampling principle in selecting Lagos area of Southwestern Nigeria, namely Lagos State and extending to Ota area of Ogun State and Ibadan area of Oyo State. This is because it responsible for 30 percent of industrial activities in Nigeria and not less than 70 percent of industrial activities in the organised private sector of Southwestern Nigeria (according to the Corporate Affairs). In the second stage, the proportionate stratified sampling technique was adopted in selecting two hundred and seventy nine (279) firms from a sample frame of one thousand and forty seven $(1,047)$ SMEs. The questionnaires were distributed to the owners/mangers of SMEs through experienced Field assistants over a period of four months.

\section{Entrepreneurial Orientation $\left(\mathbf{E O}_{\mathrm{i}}\right)$}

The entrepreneurial orientation was evaluated via the entrepreneurial orientation index $\left(\boldsymbol{E} \boldsymbol{O}_{i}\right)$. To calculate the entrepreneurial orientation index, an eighteen-item entrepreneurial measurement scale (6-items measures each of the dimensional variables of innovativeness, pro-activeness and risk taking). Seven of the questions were drawn from Covin and Slevin (1989) nine-item EO measurement scale, seven questions from Wiklund (1998), three are reconstructed from Dess and Lumpkin (2005) and one is selfconstructed. The questions from the Covin and Slevin (1989) were reconstructed from seven-point Likert Scale to five-point Likert's scale. This is not the first time of modifying EO scale, other researchers have also employed modified versions of EO scale when circumstances warranted (Dickson and Weaver, 1997; Knight, 1997; Steensma et al., 2000, Kreiser, Marino and Weaver (2002)).

The EO scale was constructed in "two-word" format on interval scale of " 1 5". As you move to the right of the scale the level of entrepreneurial orientation increases and as you move to the left, the level of entrepreneurial orientation decreases. In accordance with the 5-point Likert's scale adopted in structuring of the EO's scale, the computation and interpretation is as follows:

The entrepreneurial orientation index $\left(\boldsymbol{E} \boldsymbol{O}_{i}\right)$ :

$E O i=\frac{\text { Respondent's Responses Score }(R R S)}{\text { Total Possible Score (TPS) }}$

Where:

Respondent Response Score $(R R S)=$ Sum of the actual scores

Total Possible Score TPS) = It is the maximum possible score obtainable by a respondent 


\section{The Perceived Business Environment (PBE)}

The environmental variables of interest are dynamism, hostility, heterogeneity and Munificence. The questions drawn to get information on any of these variables were carefully selected from literature and reconstructed into five-point Likert's scale. The scores of the respondent for the items under a particular variable (let say dynamism) are summed to arrive at the assessment of the PBE from the owners/managers perspectives. The higher the score the more dynamic, hostile, heterogeneity and munificence is the $\mathrm{PBE}$ and vice versa.

\section{Data Analysis}

Prior to testing of hypothesis, a data reduction, explorative principal component analysis with varimax rotation and extraction of eigen value greater than 0.4 to reduce the effect of improper data. The exclusion of loadings below zero was based on the suggestion of Gerbing and Anderson (1988) that it is better to remove such variable with no significantly account for the variance in the construct. Thus, eleven (11) components were extracted and these were employed in the measurement of the firm's entrepreneurial orientation.

In the same vein the four PBE variables (having 5 sub-variables each) were reduced from 20-items to 13-items: comprising 4items of Dynamism, 3-items of hostility, 2items of heterogeneity and 4-items of munificence.

The Pearson correlation coefficient (r) was employed in examining the relationship between the PBE variables (dynamism, hostility, heterogeneity and munificence) and EO. Simple linear regression and multiple linear regression that has the ability to estimate the direct linear effect of a single or group of independent variable(s) on a dependent variable was employed to examine the effect of EO on growth performance of SMEs. The relative measures of the adjustment quality are: $\mathrm{R}^{2}$ and $\mathrm{R}^{2}$ adjusted squared. This statistical method is used to detect and explain the differences that each independent variable exercises on the dependent variable. The statistic software SPSS (Statistical Package for the Social Sciences) version 14 was used in analysing the data for this present study.

\section{Analysis of Result \\ The Relationship Between the nature of Business Environment (PBE) and Entrepreneurial orientation (EO)}

Based on the information in Table 1, the environmental dynamism is positively related to pro-activeness and risk-taking but negatively related to innovativeness. However, it is positively related to entrepreneurial orientation. Thus hypothesis 1 is upheld. This implies that as the PBE is dynamic, the pro-activeness and risk-taking of the firm increases. The non-significance negative relationship with innovativeness implies that in Nigerian business environment firm's innovativeness is not significantly related to the dynamic nature of the business environment.

Furthermore, environmental hostility has significant relationship only with proactiveness but not with innovativeness and risk-taking. This implies that as the environment becomes hostile, the SMEs become proactive in order to survive the hostile conditions of their PBE, risk-taking and innovativeness are thus not related to the hostility in the PBE. However, the hostility is positively related to entrepreneurial orientation because an average firm in hostile environment adopt series of innovative, proactive and risk-taking strategies and acts in order not to be washed away by the tide of "hostility". Hypothesis 2 is therefore upheld. Therefore as the business environment become hostile, the SMEs are proactive and as it becomes Benign, they becomes nonproactive (i.e. passive).

In addition, the heterogeneity of the PBE has significant relationship with all the EO's dimensional variables. It is positively related to pro-activeness and risk-taking; negatively related to innovativeness. However, there is no significant relationship between heterogeneity and entrepreneurial orientation. This implied that heterogeneity is related to the EO's dimensional variables of pro-activeness, risk-taking and innovativeness but do not have significant relationship with overall entrepreneurial orientation of the firm. Thus, the PBE become more heterogeneous the pro-activeness and risk-taking of the firm increases and as it becomes less heterogeneous the innovativeness of the firm 
increases, however, not related to the overall EO of the firm. Therefore hypothesis 3 is not accepted despite a significant relationship between the heterogeneity of the PBE and the dimensional variables of EO that determines the overall EO of the firm.

The non-significant relationship of the heterogeneity of the PBE with the EO can not be divorced from the non-uniformity of the relationship between the heterogeneity of the PBE and innovativeness on one hand and with other variables (pro-activeness and risktaking on the other hand. It implies that the positive relationship of the heterogeneity of the PBE disappears and become neutralise as a result of the negative relationship with innovativeness which is significant enough to erase the likely effect from proactiveness and risk-taking.

With respect to environmental munificence, the only significant relationship is with risk-taking, and it is negative. The relationship is neither significant with innovativeness nor proactiveness. Therefore, Hypothesis 4 is not upheld since there is no significant relationship between environmental munificence and entrepreneurial orientation. However, the significant relationship between the environmental munificence and risk-taking implied that as the PBE becomes munificence (i.e. Abundance of resources and opportunities), the risk-taking proclivity reduces and as it becomes less munificence (i.e. scarcity of resources and opportunities), the risk-taking of the firm increases. This is because the scarcity in the environment put more challenges towards the firm, thus making them to be more daring and thus more risk-taking.

Table 1: The Result of the Correlation Test for the Relationship between EO and PBE variables

\begin{tabular}{|c|c|c|c|c|c|}
\hline & & EO Index & $\begin{array}{c}\text { Innovativ } \\
\text { eness }\end{array}$ & $\begin{array}{c}\text { Proact_Inde } \\
\mathrm{x}\end{array}$ & $\underset{\text { x }}{\text { Risking_Inde }}$ \\
\hline \multirow[t]{2}{*}{ EO Index } & Pearson Correlation & 1 & $.759(* *)$ & $.529(* *)$ & $.389(* *)$ \\
\hline & Sig. (1-tailed) & & .000 & .000 & .000 \\
\hline \multirow[t]{2}{*}{ Total_Dynamic } & Pearson Correlation & $.152(* *)$ & -.064 & $.271(* *)$ & $.236(* *)$ \\
\hline & Sig. (1-tailed) & .008 & .156 & .000 & .000 \\
\hline \multirow[t]{2}{*}{ Total_Hostility } & Pearson Correlation & $.112(*)$ & -.019 & $.261(* *)$ & .015 \\
\hline & Sig. (1-tailed) & .038 & .382 & .000 & .408 \\
\hline \multirow{2}{*}{$\begin{array}{l}\text { Total } \\
\text { Heterogeneity }\end{array}$} & Pearson Correlation & -.008 & $-.250(* *)$ & $.290(* *)$ & $.185(* *)$ \\
\hline & Sig. (1-tailed) & .448 & .000 & .000 & .002 \\
\hline \multirow{2}{*}{$\begin{array}{l}\text { Total_Munificenc } \\
\text { e }\end{array}$} & Pearson Correlation & -.057 & .052 & -.093 & $-.171(* *)$ \\
\hline & Sig. (1-tailed) & .183 & .204 & .069 & .003 \\
\hline
\end{tabular}

\section{Conclusion}

This study makes contribution to the literature on entrepreneurship examining the relationship between $\mathrm{EO}$ and the nature of the perceived business environment To the best of our knowledge, such studies have not be researched in this part of the world. Thus, it will provide basic information needed by researchers into EO firms in Nigeria and will be of high relevance to those who are doing comparative studies on EO at any locations across the world. This research complements existing studies, and the results suggest that environmental variables affect the entrepreneurial orientation of firms in Nigeria.

The environmental variable of dynamism and hostility are positively related to EO and its dimensional variables of proactiveness and risk-taking. However, Dynamism has negative relation with innovativeness, while hostility has nonsignificant relation with innovativeness. The other environmental variables of heterogeneity and munificence did not have significant relations with the overall 
entrepreneurial orientation of the firm but with its dimensional variables of proactiveness and risk-taking.

The significant effect of environmental variables suggested that they are important in improving the entrepreneurial orientation of firms. In as much as studies (Burgelman, 1983; Kanter, 1982; Lumpkin and Dess, 1996; Naman and Slevin, 1993) have established that entrepreneurial orientation of a firm has positive effect on their performance, it becomes necessary to improve these environmental variables in other to improve the EO and thus take advantage of the positive relationship between the EO and firm performance to improve the performance of Nigerian SMEs.

Towards achieving this end, it is therefore recommended that:

(a) The government should promote the dynamism of the PBE by making the business environment to be a Knowledge-driven economy that supports technological change and promote innovativeness.

(b) Although, hostility has positive relation with EO. This is so because of extrachallenges facing the firm that make them proactive and risk-taking, however, at the detriment of innovativeness. Thus, for the

\section{References}

Aldrich, H. and Baker, T. (1997): Blinded by the cities? Has there been progress in the Entrepreneurship field? In D Sexton and R Smilor (eds), Entrepreneurship 2000. Chicago, IL: Upstart Publishing Company

Aloulou W., Fayolle A., Lyon B.M., and France C (2005): "A Conceptual Approach of Entrepreneurial Orientation within Small Business Context". Journal of Enterprising Culture, Vol.13, No.1, pp 21-45.

Blackman, A.J. (2003), Entrepreneurs: Interrelationships between their characteristics, values, expectations, management practices and SMEs performance. Ph.D Thesis submitted to Department of Management, Griffith University. Australia

Brown, T. E. and Kirchhoff, B. A. (1997), "The Effects of Resource Availability and Entrepreneurial Orientation on firm Growth", Frontiers of Entrepreneurship Research. Babson College positive effect the $\mathrm{EO}$ has on performance to be achieved the government should make the environment to be more benign by ensuring that the unnecessary interference by government officials do not become a great threat, boosting SMEs economy and aversion of price-war in the Nigerian industrial sector, particularly, the SMEs subsector.

(c) Promote environmental munificence by making accessibility to resources and customers to be relatively easy, promote growth opportunities in SMEs industries in terms of infrastructural facility (e.g. roads, electricity and water), established selfregulating standardisation of quality control system of international standard in Nigerian Industries and removes unnecessary bottlenecks in production of goods and services in Nigerian business environment.

In essence, the government should make the environment to be friendly, relatively stable, heterogeneous, benign and munificent. In order to promote innovativeness and entrepreneurship in our SMEs and thus improved performance, since innovativeness is the centre-piece of entrepreneurship and entrepreneurship is the driving force of industrial growth and development.

Burch, J. G. (1986), 'Entrepreneurship' New York: John Wiley and Sons.

Burgelman, R. A. 1983. Corporate entrepreneurship and strategic management: Insights from a process study. Management Science, 29: 1349-1364.

Bygrave, W.D. and Hofer, C.W. (1991). "Theorizing about Entrepreneurship." Entrepreneurship: Theory and Practice, 16(2), 13-22.

Chandler, G. N., and Hanks, S. H. (1994). Founder competence, the environment, and venture performance. Entrepreneurship Theory and Practice, 18(3), 77-89.

Covin, J.G. and Slevin, D. P. (1986). The development and testing of an organization level entrepreneurship scale. Frontiers of Entrepreneurship Research.

Covin J. and Slevin, D.(1989), Strategic Management of Small Firms in Hostile and Benign Environments. Strategic Management Journal, 10(1), pp. 75-87. 
Covin, J. G. and Slevin, D. P. 1991. A conceptual model of entrepreneurship as firm behavior. Entrepreneurship theory and practice(Fall): 7-25.

Gerbing, D.W. and Anderson, J.C. (1988), 'An Updated Paradigm for Scale Development Incorporating Unidimensionality and Its Assessment', Journal of Marketing Research 25 (May), pp. 186-192.

Gilbert, J. and G. Jones (2000), 'Managing Human Resources In New Zealand Small Businesses', Asia Pacific Journal of Human Resources 38(2): 55-67.

Gupta, A. K. and Govindarajan, V. (1984), "Business Unit Strategy, ManagerialCharacteristics, and Business Unit Effectiveness at Strategy Implementation", Academy of Management Journal, 27, pp. 25-41.

Hart, S. 1992. An integrative framework for strategy-making process. Academy of Management Journal, 17: 327-351.

Kanter, R. M. (1983). The Change Masters: Innovation and Entrepreneurship in the American Corporation. New York: Simon and Schuster.

Khandwalla, P. N. 1987. Generators of pioneering-innovative management: Some Indian evidence. Organization Studies, 8(1): 39-59.

Lumpkin, G. T., and Dess, G. G. (1996). Clarifying the entrepreneurial orientation construct and linking it to performance. Academy of Management Review, 21(1), 135172.

Lumpkin, G. T. and Dess, G. G. (2001), 'Linking two dimensions of entrepreneurial orientation to firm performance: The moderating role of environment and industry life cycle', Journal of Business Venturing, 16: 429-451.

Miles, R. E. and Snow, C. C. (1978), 'Organizational strategy, structure and process', New York: McGraw-Hill.
Miller, D. and Friesen, P. H. (1978), 'Archetypes of Strategy Formulation', Management

Science, 24(9): 921-933.

Miller, R.W. and Tolouse, J. M. (1988)

Strategy, Structure, CEO Personality and Performance in Small Firms, American Journal of Small Business (Winter), pp.47-61.

Mintzberg, H. (1973), 'Strategy Making in Three Modes'. California Management Review, 16(2): 44-53.

Naman, J.L. and Slevin, D.P. (1993), 'Entrepreneurship and Concept of Fit: A Model and Empirical Tests', Strategic Management Journal. Vol 14, pp. 137-153.

Venkataraman, S. (1997), "The distinctive domain of entrepreneurship research." In J. A. Katz (Ed.), Advances in Entrepreneurship, Firm Emergence, and Growth, 3, 119-138. Wiklund, J. (1999), 'The Sustainability Of The Entrepreneurial Orientation-Performance Relationship, Babson College.

http://www.babson.edu/entrep/fer/papers $99 / X$ XXI/XXXI_B/XXXI_B\%20Text.htm

Wiklund, J. (1998). Entrepreneurial orientation as predictor of performance and entrepreneurial behaviour in small firmslongitudinal evidence. In Frontiers of Entrepreneurship Research. Wellesley, MA: Babson College. http://www.babson.edu/entrep/fer/papers98/I X/IX_E/IX_E_text.htm

Wiklund, J., D. Shepherd. (2003), "Knowldege-Based Resources, Entrepreneurial Orienataion, and the Performance of Small and Medium-sized Businesses". Strategic Management Journal, 24: 1307-1314.

Zhan, J Deschoolmeester, D and Vlerick, L (2004), 'Exploring entrepreneurial orientation (EO) in 3 dimensions: a new prospective for analyzing the value of a company'. http://www.kmu.unisg.ch/rencontres/RENC20 04/Topics/Deschoolmester_Renc_04_Topic_ D.pdf 